\title{
The Antibacterial Activity of Leaf Extracts of Ocimum Gratissimum and Sida Acuta
}

\author{
*Mbajiuka Chinedu Stanley ${ }^{1}$, Obeagu Emmanuel Ifeanyi ${ }^{2,}$ Ochei Kingsley \\ Chinedum $^{3}$ and Nnadi Doris Chinenye ${ }^{4}$ \\ 1.Lecturer,Department of Microbiology,Michael Opkara University of Agriculture,Umudike,Abia State,Nigeria. \\ 2.Medical Laboratory Scientist,Diagnostic Laboratory Unit,University Health Services Department, Michael \\ Opkara University of Agriculture,Umudike,Abia State, Nigeria. \\ 3.Department of H.S.S. and Laboratory,FHI 360 Country Office,Plot 1073-AI Garki,Abuja,FCT,Nigeria. \\ 4. Department of Microbiology,Michael Opkara University of Agriculture,Umudike,Abia State,Nigeria.
}

\begin{abstract}
The antibacterial activities of ethanolic and aqueous extracts of Sida acuta and Ocimum gratissimum on Escherichia coli, Staphylococcus faecalis and Peudomonas aeuginosa were determined using disc diffusion assays. All the extracts exhibited moderate to high level of inhibtion against the four microorganisms.The antibacterial activities were measured by the diammeter by dimeter zone of inhibiton, in which ethanolic extracts of Sida acuta exhibit the highest yield which is $18 \mathrm{~mm}$ and the lowest yield in aqueous(cold) extract $7 \mathrm{~mm}$. The minimum inhibitory concentration (MIC) is $0.125 \mathrm{mg} / \mathrm{ml}$ on both plant extracts using the ethanollic extracts of Sida acuta and Ocimum gratissimum were positive on both the four microorganism and the minimum inhibitory concentration(MIC) were also positive and gram negative organisms. This research is discussed in relation to the accepatable herbal medicines as a means of disease control.

Keywords:Ocimum gratissimum,Sida acuta,Minimum Inhibitory Concentration, Escherichia coli,Staphylococcus faecalis and Peudomonas aeuginosa.
\end{abstract}

\section{Introduction}

Medicinal plants are distributed worldwide, but they are most abundant in the tropical countries(Calixto,2000).It is estimated that plant materials are presently in or have provided th models for 50\% western drugs.A relative small percentage of medical plants are used as food for both humans and other animals species, it is possible that even more are used for medicinal purposes.

Plants based on antimicrobials have therapeutic potentials. They are used for effective treatment of infection disease yet gently.An example is Hydratics canadensis, not only does it has antimicrobial activity but also increase blood supply to the spleen releasing mediating compounds (Murray et al.,1995). Also, Xytopia aethiopica has an attractive aroma and has been applied in ethno medicine in the treatment of cough,bronchitis,dysentery and female fertilization.

Iwu (1993) reported that infectious disesae accounts for one half of all deaths in the tropical countries irespective of efforts made in controlling the incidence of epidemic.Most food-borne disesase due to poor hygiene can be life threatening and need antibiotic therapy but most of the causative agents have already developed resistance to common antibiotics in many countries (Iwu, 1993).This resistance has been reported in Ethiopia in Africa.Due to absence of modern healthcare system in most rural areas,people decided to visited traditional healer who use medicinal plants to treat their patients with the recent adavances made in using plant extracts in inhibiting microbial growth,it was observed that phytomedicines have antimicrobial effect against some human pathogens such as Staphylococcus aureus, Escherichia coli,etc.

Many plants extracts have shown to acquire antibactreial properties active against many microoganisms inside the body or in vitro for example Garcina biflavonone have been found to be active against variety or organism like Staphylococcus aureu and Escherichia coli(Iwu,1993).It is used used in the treatment of liver disorder bronchitis as a chewing stick and throat infections (Lamidi et al., 1995). Some extracts of green pepper,garlic and onion have noticed to inhibit the growths of Shigella dysentria,Salmonella typhosia(Sofowora,1983).Ocimum gratissimum and Sida acuta are also medicinal herbs in Nigeria used in treatment of some infectious disease.

Ocimum gratissimum is used as vegetable for soup prepartions which exhibits hot and spicy taste and are consumed during cold season.It is claimed that species and herbs assist in the concentration of the uterus in postpartum women (Okwu, 2003).

Hpwever, it is generally assumed taht the active dietary constituents contributing to those medicinal properties exhibited by herbs and species are the phytochemical vitamins and minerals. The Ocimum oil is active against several species of bacterial and fungi,for example shigella,salmonella,proteus, Trichophyton rubrum etc (El-said 
et al., 2000). Ocimum gratissimum is rich in alkaloids,tannins,phylates flavnoids and Oligosaccharides and it has tolerable cyanogenic glycoside content (Ijeh et al.,2004) which is the chemical compound active against microorganisms.

Sida acuta is a marvelous weed that frequently dominates improved pastures, waste and disturbed places roadsides (Mann et al., 2003). The decribed pharmacological properties of the plants involve the antiplsamodial,antimicrobial,antioxidant,and many other properties.Some studies resulted in the isolation of single compounds while the others just demontrated the activity of the crude extracts.

Medicinal plants as Sida acuta and ocimum gratissimum have been asserted to provide various culinary and medicinal properties. These medicinal properties exerts bacteriostatic an dbacteriocidal effects on some bacteria.These effects have been attributed to the peptides,alkaloids essential oil,flavonoids etc which are the major compounds in these plants (Okigbo and Igwe, 2007).

This study was done to determine the inhibitory properties of ocimum gratissimum and Sida acuta on four strains of bacteria of which are Staphylococcus areus, Streptococcus faecalis, Peudomonas aeruginosa and Escherichia coli using ethanol and aqueous as solvent for extraction. It is also used to measure the zone of inhibition of these plants on the organism.

\section{MATERIALS}

\section{Materials And Methods}

Materials used in this study were collected in the laboratories of Nation Root Crop Research Institute (NRCRI) Umudike and the department of Microbiology in Michael Okpara University of Agriculture,Umudike.Except the two plants which were collected from the laboratory of the Federal Medical Centre,Umuahia.

\section{METHODS}

\section{COLLECTION OF PLANT MATERIALS}

The medicinal plants used in this study were the leaf of Ocimum gratissimum and Sida acuta.Fresh samplse of Ocimum gratissimum leaves were collected from an uncultivated farmland at Nsukka in Enugu State, while the fresh leaves of Sida acuta were collected from road side in Nsukka,Enugu State.The plants were identified and authenticated at the Botany Department,Michael Okpara University of Agriculture,Umudike by a taxonomist Dr.I.C.Okwulehe.The leaves of each plant was washed thoroughly under running water and dried uder room temperature. They were grinded into powder and stored in air tight bottles.

\section{STERILIZATION OF MATERIALS}

All material were washed the detergent and rinsed thoroughly. They were placed in a rack to dry and then autoclaved at $121^{\circ} \mathrm{C}$ for 15 minutes to kill microorganisms.

\section{TEST MICRIORGANISM}

The strain used in this work was Staphylococcus aureus, streptococcus faecalis, Pseudomonas aeruginosa and Escherichia coli. They were all coolected at alboratory in Federal Mediacl Centre Umuahia and their viability were tested by resuscitating them in buffered peptone broth and then sub-cultured in Nutrient agar medium at $37^{\circ} \mathrm{C}$ for 3 hours prior to antibacterial testing.

\section{PREPARATION AND EXTRACTION OF THE PLANTS ETHANOL EXTRACTS}

The ethanol extracts wsa prepared by weighing out twenty grams $(20 \mathrm{~g})$ of the powdered leaves of Ocimum gratissimum and Siad acuta in different conical fllask and adding $200 \mathrm{ml}$ of ethanol in each and stirring vigorously with a glass rod and left for 24 hours. They were filterd off with the sterile filter paper(Whatman No 1 filter paper) into a clean conical flask and filterates was transferred into the sample holder of the rotary vacuum evepoartor where the solvent was evaluated at room temperature of $28^{\circ} \mathrm{C}$. The standard extracts obtained were then stored in refrigerator at $4^{0} \mathrm{C}$ until when required for use.

\section{COLD WATER EXTRACTS}

The cold water extracts aws prepared by weighing out twenty grams $(20 \mathrm{~g})$ of the powdered leaves of Ocimum gartissimum and Siad acuta in different conical flask and adding 200ml of cold water in each stirring vigorously with aglass rod and left for 24 hours. They were filterd off with sterile filter paper (Whatman No 1 filter paper) into a clean conical flask and the filterates was transferred into a sample holder of the rotary vacuum evaporation where the cold water solvent was evaporated at its room temperature at $28^{0} \mathrm{C}$. The standard extracts obtained were then stored in a refrigerator at $4^{0} \mathrm{C}$ until when required for use. 


\section{DISC DIFFUSION ASSAY}

The disc diffusion method was adopted for the determination of the antibacterial activity of extract. Whatman No 1 filter paper was used with slight modification. The filter paers were cut into disc of $6 \mathrm{~mm}$ in diameter using a perforator. The discs were treated by boiling for 30 minutes, the reason was to destroy chemicals used in preserving the filter paper and also to avoid the inhibitor of the antimicrobial action of the extracts on test organisms. After boiling, the disc was sterilized by autaclaving for 15 minutes and were stored in a sterile bottle for use.

\section{PREPARATION FOR CULTURE MEDIA}

Muella Hinton agar was prepared by weighing 38 grams of the powdered agar into $100 \mathrm{ml}$ of distilled water in a clean conical flask.It was soaked for 20 minutes and then covered with a foil andwasautoclaved at $121^{\circ} \mathrm{C}, 115$ atmospheric pressure for 15 minutes. The medium was cooled to $50^{\circ} \mathrm{C}$ and $20 \mathrm{ml}$ of the medium was poured into a sterile glass petri dish and allowed to solidify. The sterility of the medium was tested by allowing it to stay overnight and checking for contamination.

A flaming wire loop is being used to pick an organism and stick it well on a prepared media.After that the paper disc is picked with a sterilized wire loop and use it to collect the extarct then place it on the media in which the organism is stick on. Then covered well and incubated for 24 hours at $37^{\circ} \mathrm{C}$.

After an overnight incubation at $37^{\circ} \mathrm{C}$, the zone inhibition was measured and recorded.The test was carried out in duplicates of different organisms with different extracts.

\section{DETERMINATION OF MINIMUM INHIBITORY CONCENTRATION}

A stock solution of $100 \mathrm{mg} / \mathrm{ml}$ of ethanol and cold water extracts were prepared. $0.4 \mathrm{ml}$ of the sloution of Sida acuta and Ocimum gratissimum is diluted to $20 \mathrm{ml}$ with the nutrient broth.Serial dilutions were prepared to obtain the following concentrations:400,200,100,50,25,12.25mg/ml.0.0ml of the suspensions of overnight cultures of the test organisms which was adjusted to McFaralnd standard.The organism is stricked on the agar medium,using a cut borer to make wholes on the medium.Different concentrations of the extracts were added into the wholes and were covered and incubated for 24 hours at $37^{\circ} \mathrm{C}$ (Ekundayo and Ezeogu,2006). The zones of inhibition were measured,and the least concentration of each extracts that inhibited microbial growth after the incubation period wsa taken on the MIC.

\section{CONTROL EXPERIMENT USING GENTAMYCIN AND TETRACYCLINE}

Gentamycin and Tetarcycline were used as a control in order to compare the diameter of zone of inhibition from the extracts and already standardized antibiotics and it was carried out aseptically. This is to ensure the prescription of either antibiotics or plants herbs for antibacterial activities.

Gentamycin and tetracycline (250mg) capsule was dissolved to get a stock solution of 50,000mg/ml.0.4ml of these solutionswee taken to make up $\mathrm{t} 10 \mathrm{ml}(0.4 \mathrm{ml}+9.6 \mathrm{ml})$ of distilled water. $20 \mathrm{ml}(0.2 \mathrm{ml})$ of the dilution was dropped on each disc.Thes discs were placed on the inoculated culture medium along side the aqueous and ethanol extracts.

\section{PERCENTAGE YIELD OF PLANT EXTRACT}

The yields of the plant extracts(ethanol and aqueous) were calculated as percentages of the initial powdered sample of plant materials shown in table 3 below. The ethanol extracts of Ocimum gratissimum gave the highest yield which is $8.5 \mathrm{~g}$ representing $40 \%$, while the ethanol extract of Sida acuta yields $7.5 \mathrm{~g}$ representing $35 \%$.The percentage yields of aqueous extracts of Ocimum gratissimum and Sida acuta were $30 \%$ and $25 \%$ respectively.

\section{ANTIBACTERIAL ACTIVITY OF PLANT EXTRACTS}

The antibacterial activities of the extraction of two plant extracts were measured by the diameter zone of inhibition using the disc agar assay and by using serial dilution to determine the minimum inhibitory concentration (MIC) of the extracts. The summary of the diameter zone of inhibition produced by the plants extract against the organisms is shown below in table 4.The ethanol extract of Sida acuta had the zone of inhibition of $18 \mathrm{~mm}$ on Staphylococcus aureus and Streptococcus faecalis it yielded $14 \mathrm{~mm}$. The diameter zone of inhibition of the ethanol extarcts on Escherichia coli is 16mm,while Pseudomonas aeruginosa yielded $14 \mathrm{~mm}$. The aqueous extract of Sida acuta had diameter zone of inhibition of 10mm,on both Staphylococcus aureus and Pseudomonas aeruginosa and $12 \mathrm{~mm}$ on both Escherichia coli and Streptococcus faecalis.

On Ocimum gratissimum in the ethanol extract yields $13 \mathrm{~mm}, 15 \mathrm{~mm}$ and $12 \mathrm{~mm}$ on Staphylococcus aureus, Streptococcus faecalis. Escherichia coli and Pseudomonas aeruginosa respectively while its aqeous extract 
yield 7mm,6mm,8mm, and $8 \mathrm{~mm}$ on Staphylococcus aureus, Streptococcus faecalis. Escherichia coli and Pseudomonas aeruginosa respectively

Table 3 shows the minimum inhibition concentration in Staphylococcus aureus using the plant extarcts in which its ethanolic extracts had minimum inhibition concentration of 0.125 on both extracts.Tables 4,5 , and 6 also shows the minimum inhibition concentration on Streptococcus faecalis, Escherichia coli and Pseudomonas aeruginosa. Escherichia coli had the lowest minimum inhibition concentartion which is 0.0625 on ethanolic extracts of Sida acuta.

Gentamycin(control) show a wide zone of inhibition on both Escherichia coli and Staphylococcus aureus as $32 \mathrm{~mm}$ and $24 \mathrm{~mm}$ or Ocimum gratissimum and $25 \mathrm{~mm}$ and $20 \mathrm{~mm}$ on both organisms but in Sida acuta. While tetracycline(control) yield $22 \mathrm{~mm}$ and $10 \mathrm{~mm}$ on both organisms in Ocimum gratissimum and $30 \mathrm{~mm}$ and $26 \mathrm{~mm}$ on both organisms by Sida acuta

TABLE 1:THE PERCENTAGE OF THE CRUDE EXTRACTS OF Ocimum gratissimum and Sida acuta

\begin{tabular}{llccc} 
Plant species & Extracts & $\begin{array}{c}\text { weight of the } \\
\text { Powdered sample }\end{array}$ & $\begin{array}{c}\text { weight of the } \\
\text { extracts recovered }\end{array}$ & $\begin{array}{c}\text { percentage yie } \\
\text { of extracts }\end{array}$ \\
\hline Ocimum & Aqueous & $20.0 \mathrm{~g}$ & $6.0 \mathrm{~g}$ & $30 \%$ \\
Gratissimum & ethanol & $20.0 \mathrm{~g}$ & $8.5 \mathrm{~g}$ & $40 \%$ \\
Sida acuta & Aqueous & $20.0 \mathrm{~g}$ & $5.0 \mathrm{~g}$ & $25 \%$ \\
& Ethanol & $20.0 \mathrm{~g}$ & $7.5 \mathrm{~g}$ & $35 \%$ \\
\hline
\end{tabular}

TABLE 2:ANTIBACTERIAL ACTIVITY OF THE EXTRACTS WITH DIAMETER ZONE OF

\begin{tabular}{lcclcc}
\hline \multicolumn{2}{l}{ INHIBITION } & & & & \\
Plant & Extract type & E.coli & S.faecalis & P.aeruginosa & S.aureus \\
Species & Aqueous & $8 \mathrm{~mm}$ & $6 \mathrm{~mm}$ & $8 \mathrm{~mm}$ & $7 \mathrm{~mm}$ \\
\hline Ocimum & Ethanol & $15 \mathrm{~mm}$ & $10 \mathrm{~mm}$ & $12 \mathrm{~mm}$ & $13 \mathrm{~mm}$ \\
gratissimum & Gentamycin & $32 \mathrm{~mm}$ & - & - & $24 \mathrm{~mm}$ \\
& Tetracycline & $22 \mathrm{~mm}$ & - & - & $10 \mathrm{~mm}$ \\
Sida acuta & Aqueous & $12 \mathrm{~mm}$ & $12 \mathrm{~mm}$ & $10 \mathrm{~mm}$ & $10 \mathrm{~mm}$ \\
& Ethanol & $16 \mathrm{~mm}$ & $14 \mathrm{~mm}$ & $14 \mathrm{~mm}$ & $18 \mathrm{~mm}$ \\
& Gentamycin & $25 \mathrm{~mm}$ & - & - & $20 \mathrm{~mm}$ \\
& Tetracycline & $30 \mathrm{~mm}$ & - & - & $26 \mathrm{~mm}$ \\
& & & & &
\end{tabular}

TABLE 3:THE MINIMUM INHIBITION CONCENTRATIONS ON Staphylococcus aureus by the two PLANT EXTRACTS USED.

Plant extracts Different concentration of the extracts

\begin{tabular}{|c|c|c|c|c|c|c|c|c|}
\hline 1.0 & 0.25 & 0.125 & 0.0625 & 0.0315 & MIC & & & \\
\hline Sida acuta & $\begin{array}{l}\text { Aqueoeus } \\
\text { (Cold) }\end{array}$ & 10 & 7.6 & 5.6 & 0 & 0 & 0 & 0.25 \\
\hline Ethanol & 20.6 & 14.6 & 11.0 & 7.3 & 0 & 0 & 0.125 & \\
\hline Ocimum Aqueous & 7.0 & 5.6 & 3.3 & 0 & 0 & 0 & 0.25 & \\
\hline
\end{tabular}

\begin{tabular}{cccccccc} 
Ethanol & 13.0 & 9.5 & 7.6 & 5.3 & 0 & 0 & 0.125 \\
\hline KEYS : MIC=MINIMUM INHIBITION CONCENTRATION & &
\end{tabular}
TABLE 4:THE MINIMUM INHIBITION CONCENTRATIONS OF THE EXTRACTS ON
Streptococcus faecalis by two PLANT EXTRACTS

Plant extracts Different concentration of the extracts

\begin{tabular}{ccccccccccc}
$\mathbf{1 . 0}$ & $\mathbf{0 . 5 0}$ & 0.25 & 0.125 & 0.0625 & 0.0315 & MIC & & & \\
\hline Sida acuta & Aqueoeus & 12.0 & 9.6 & 5.6 & 0 & 0 & & 0 & 0.25 \\
Ethanol & (Cold) & 14.0 & 10.3 & 6.3 & 0 & 0 & & 0 & 0.25 & \\
Ocimum Aqueous & 6.0 & 5.6 & 0 & 0 & 0 & 0 & 0.5 &
\end{tabular}

Gratisssimum (Cold)

\begin{tabular}{llllllll} 
Ethanol & 10.0 & 7.6 & 6.3 & 5.6 & 0 & 0 & 0.125 \\
\hline
\end{tabular}


The Antibacterial Activity of Leaf Extracts of Ocimum Gratissimum and Sida Acuta

\section{TABLE 5:THE MINIMUM INHIBITION CONCENTRATIONS OF THE EXTRACTS ON Escherichia coli by two PLANT EXTRACTS}

\begin{tabular}{|c|c|c|c|c|c|c|c|}
\hline Plant extracts & \multicolumn{7}{|c|}{ Different concentration of the extracts } \\
\hline 1.0 & 0.25 & $0.125 \quad 0.0625$ & 0.0315 & MIC & & & \\
\hline Sida acuta & $\begin{array}{l}\text { Aqueoeus } \\
\text { (Cold) }\end{array}$ & $12.0 \quad 9.6$ & 5.6 & 0 & 0 & 0 & 0.125 \\
\hline Ethanol & 18.0 & 14.610 .3 & 9.5 & 6.6 & 0 & 0.0625 & \\
\hline Ocimum Aqueous & 12.0 & 9.68 .0 & 5.6 & 0 & 0 & 0.125 & \\
\hline Gratisssimum & (Cold) & & & & & & \\
\hline Ethanol & 15. & $\begin{array}{lll}0 & 12.0 & 9.3 \\
\end{array}$ & 6.6 & 0 & 0 & 0.125 & \\
\hline
\end{tabular}

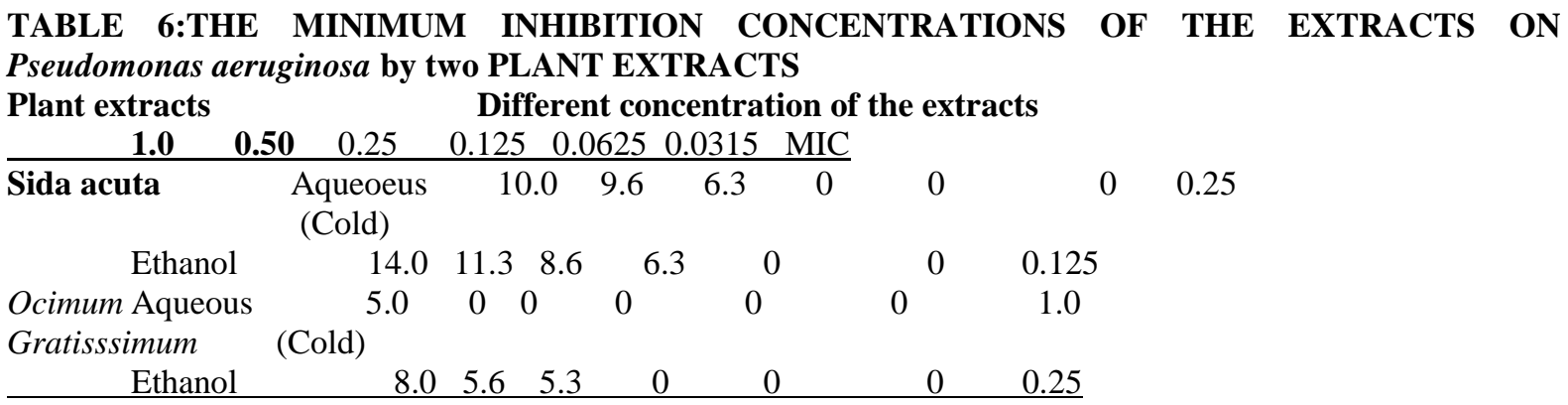

\section{Discussion}

The inhibitory activities of ethanolic extarcts of Ocimum gratissimum and Sida acuta were found to be little greater than aqueous(cold) crude extracts according to Sofowora(1993) the active principles of the plant herb may be more soluble in ethanol as employed in traditional medicine.

In this study reported here,the aqueous(cold) extarcts of Ocimum gratissimum and Sida acuta showed the zone of inhibition to all the organisms used which are Pseudomonas aeruginosa,Escherichia coli,Streptococcus faecalis and Staphylococcus aureus. This result almost correspond to the findings of Lewis and Elvin(1995) who in thier work found the weak antibacterial activity on the extarcts on both gram positive and gram negative organisms.

The ethanol extracts of Ocimum gratissimum and Sida acuta which showed a greater zone of inhibition to all organisms used.This also correspond to the findings of(Onajiobi,1986) who in their work found that this plants can be useful in treating some infectious disease such as diarrhoae,haedache,skin disease,pneumonia,fever,gum disorder etc.

The effectiveness of antimicrobial agent varies with the nature of organisms being treated.Since microorganisms differ markedly in their susceptibility.The presence of the active principles in plants is influenced by several factors such as age of the plants,method of extraction and extracting solvent.It is possible that the leaves of the Sida acuta and Ocimum gratissimum contains high concentration of the antimicrobial compounds or different antimicrobial agents based on the values of minimum inhibition concentration and the zone of inhibitions.

However,there was a based a broad spectrum activity observed on the two plants extracts which are Ocimum gratissimum and Sida acuta as it showed high activity against both gram negative and gram positive tested.

\section{Conclusion}

Ocimum gratissimum and Sida acuta are plant of wide usage in traditional medicine.The results of this work,now demonstrated that these plants were active on several bacterial starins such as Pseudomonas aeruginosa,Escherichia coli,Streptococcus faecalis and Staphylococcus aureus.

\section{References}

[1] Calixto,J.B.(2000).Efficiency,Safety,Quality Control Marketing and Regulatory Guideline for Herbal Medicines(Phytotherapeutic Agents).Brazil Journals of Medical and Biological Research 33:179-189.

[2] Ijeh,I.I.,Njoku,O.U. and Ekenze,E,C.(2004).Medicinal Evaluation of Xylopia Ethopica and gratissimum.Journal of Medical Aromatic Science 14:283-285.

[3] El-said,F.,Sofowora,E.A.,Malconm,S.A.,Alfer,A.(1996).An Investigation inti the Efficacy of Ocimum gratissimum as used in Nigeria Native medicine.Planta dedica.17:195-200.

[4] Iwu,M.M.(1993).Handbook of African Medicinal Plants.CRC.Press Boca Baton,pp.11-15.

[5] Lamidi,M.E.,Oliver,R.,Faure,L.,Debrauweri,L.,Nze-ekukang and Balansard,G.(1995).Quino Vic Acid Glycolysides.Journal Planta Medica 6:280-281.

[6] Murray,M.(1995).The Healing Power of Herb.Prima Publishing Bocklin.pp.162-171.

[7] Lewis,W.H. and Levis,M.P.(1995).Medicinal Plants as Source of New Therapeutic.Journal of Botanical Garden.82:16-24.

[8] Okigbo,R.N. and Igwe,M.(2007).The Antimicrobial Effects of Piper Giuneense and Phyllantus Amarus on Candida albicans and Streptococccus faecalis.Immunological.Hungeria.54(4):354-366. 
[9] Okwu,D.E. and Ekeke,O.(2003).Phytochemical Composition of Chewing Sticks in South Eastern Nigeria.Global Journal of Pure and Applied Science (9):235-230.

[10] Onajobi, F. D. (1986). Smith Muscle Sontrating lipids Soluble Principles in Chromfractions of Ocimum Gratissmum. Journal of Ethnopharmaeology. 18: 3-11

[11] Sofowora, E. A. (1983). An address proceedings on the 5th international Symposition on Medicinal Plants. Published at University at University of Ile-Ife Ngeria. Page. 7.

[12] Sofowora, E. A. (1993). Antimicrobial Properties of Tannis. Journal of Phytochemistry. 30: 2875-2883.

[13] Mann, A., Gbate, M., and Umar, A.N (2003).Sida acuta Subspecie acuta Medicinal and Economic Plant of Nupeland. Jube Evans Books and Publication, page 241. 